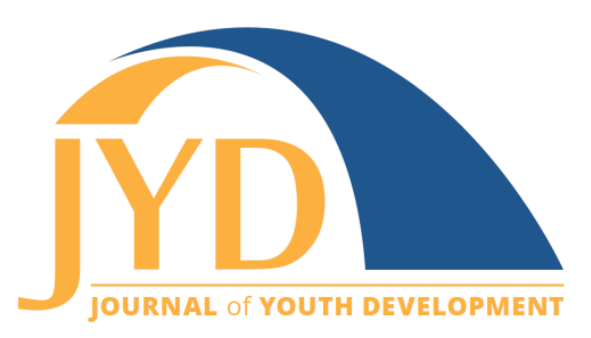

http://jyd. pitt. edu/ | Vol. 14 Issue 2 DOI 10.5195/jyd.2019.710 | ISSN 2325-4017 (online)

\title{
Christian Faith in the Immigration and Acculturation Experiences of Filipino American Youth
}

\author{
M. Gayle Gabriel \\ Texas A\&M University \\ gaylegabriel@ppri.tamu.edu
}

\begin{abstract}
The Filipino immigration experience began in the Philippines via American-modeled schools and Spanishenforced Christian Catholicism, and this historical experience may have translated to smoother acculturation experiences for Filipinos immigrating to the United States. However, a smooth acculturation experience may not be the case for all Filipino youth. The purpose of this study is to explore the impact of Christian faith in the immigration and acculturation of Filipino American youth. Data were collected through semi-structured interviews with 5 Filipino American emerging adults between the ages of 18 and 30 years old. Interview data went through 3 levels of coding and categorization; several themes were developed. Results show that Christian faith was a powerful factor in acculturation experiences for Filipino American youth. The modeling of faith was pivotal in helping them navigate through difficult childhood experiences and in some cases mental health problems. Modeling of faith also largely determined participants' own commitment to religious practices, such as attending daily mass or becoming part of a church organization. At the community level, Christian faith helped participants establish community ties, which helped ease their transition into mainstream American culture. Based on the results of this study, Christian faith is an important coping factor for Filipino American youth. Christian faith allowed participants to feel a greater sense of connection to each other and to make connections with others in the United States. Christian faith shaped participants' outlook on their lives and their day-to-day activities.
\end{abstract}

Key words: immigrant, Filipino American, Christian faith, acculturation, immigration

\section{Introduction}

The concept of acculturation has become widely used and often talked about across many fields of study, especially in the last 20 years. The term acculturation gained ground in the 1930s with

(cc) EY New articles in this journal are licensed under a Creative Commons Attribution 4.0 License. This journal is published by the University Library System, University of Pittsburgh and is cosponsored by the University of Pittsburgh Press. The Journal of Youth Development is the official peer-reviewed publication of the National Association of Extension 4-H Agents and the National AfterSchool Association. 
Redfield, Linton, \& Herskovits' (1936) classic definition as ". . . those phenomena which result when groups of individuals having different cultures come into continuous first-hand contact, with subsequent changes in the original cultural patterns of either or both groups" (p.149). This suggests that acculturation is an inconsistent process and not uniform across groups that have contact with each other. With the reform of the Immigration Act of 1965, the United States has seen an increase in multiculturalism and diversity within its population and an increased interest in how different ethnic groups acculturate and/or assimilate into American society. Since then, researchers have undertaken the inquiry into how acculturation affects different ethnic groups physically, mentally, and emotionally in the fields of sociology, public health, psychology, health education, medicine, and many others.

To gain a better understanding of how acculturation affects Asian American ethnic groups, it is important to look at ethnic groups individually. Filipinos are an Asian ethnic group that has a unique relationship to the United States. The Philippines has consistently been among the top five countries that have sent the most immigrants to the United States for the last 20 years (McNamara \& Batalova, 2015; Zong \& Batalova, 2018). The Philippine-to-United States immigration experience was primed by the 50 -year U.S. colonial experience in the Philippines that established American-modeled schools and the learning of English, on top of the Catholic conversion of a majority of the islands by 300 years of Spanish influence (Espiritu, 1995). This priming has perhaps led to a perceived smooth acculturation process for Filipino Americans and an invisible one.

Consequently, many youth programs focus a majority of their programming for White, Black, and Latino youth. While there is demonstrated need for programming for these groups, Filipino American youths' needs may be overlooked by youth development practitioners based on the model minority assumption (Chou \& Feagin, 2008). In this assumption, Asian Americans-which include Filipino Americans-are perceived to have better health, educational, and social outcomes than their Black or Latino counterparts. Regrettably, this has been influential in the failure to recognize and address Filipino American needs, especially in Texas, which has the third largest Filipino American population behind California and Hawai'i (McNamara \& Batalova, 2015; Zong \& Batalova, 2018).

One area that warrants a deeper look is the role of Christian faith in Filipino American life. "Filipinized" (meaning taking on characteristics or aspects of Filipino culture through Filipino membership) church communities on the West Coast and in Texas have provided cultural continuity between the Philippines and the United States, which has helped ease the culture 


\section{Faith and Filipino Immigration and Acculturation}

shock Filipino immigrants experience (Cherry, 2014; Gonzalez, 2009). However, this link between the church and the community has not completely mitigated the issues surrounding acculturation to the United States. Importantly, there is a dearth of literature looking at the impact of Christian faith for Filipino American youth-a population that is often understudied.

\section{Purpose}

Yin (2009) described case studies as a method used to "understand complex social phenomena that allows investigators to retain the holistic and meaningful characteristics of real-life events" (p.4). The purpose of this study was to explore the impact of Christian faith in the immigration and acculturation experiences of Filipino American youth using case studies, more particularly collective case studies. This research design allowed the author to explore deeply the issues surrounding participants' immigration experiences and their processes of acculturation.

\section{Methods}

The following study was a collective case study, which focused on one issue or concern that was present across all cases (Creswell, 2013; Stake, 1995). This approach aims to explore a phenomenon such as the practice of Christian faith in Filipino American youth immigration and acculturation experiences, rather than assessing such a phenomenon. A case design such as this also provides multiple perspectives to an issue and adds depth and clarity to the issue being investigated (Baxter \& Jack, 2008). This was appropriate for this study as the goal was to gain a deeper understanding of how Christian faith is operationalized in the immigration and acculturation experiences of Filipino American youth.

\section{Sampling}

Snowball sampling strategy was used to identify and contact potential participants. This strategy was chosen purposefully for its flexibility and the emergent nature of the research (Patton, 2015). Data for this study were collected using semi-structured interviews with consenting participants. Participants chose a location in which they were comfortable being interviewed and a time that worked best for their schedules. The author conducted interviews in four different cities across the state of Texas, and interviews lasted between one and three hours. Further, once interviews began it was found that 1-hour interviews were not long enough to gain an in-depth understanding of participants' experiences. Therefore, the sample 
Faith and Filipino Immigration and Acculturation

size was treated flexibly to allow for longer interviews with fewer participants (Creswell, 2013; Patton, 2015).

\section{Case Selection}

Selecting cases for this study occurred after all interviews with participants concluded. To gain an in-depth understanding of the impact of Christian faith in Filipino American youth experiences, the author focused on cases where information about participants' Christian faith and use was particularly rich (Patton, 2015). The sample participants for this study $(n=5)$ were one male and four females. The limit of $n=5$ participants still allowed for the promotion of validity and reliability of the data due to saturation of the common themes among participants (Creswell, 2013; Lincoln \& Guba, 1985; Merriam \& Tisdell, 2016; Patton, 2015). As Patton (2015) recommended, information-rich cases were included in this study.

\section{Profile of Participants}

The mean age of participants was 22 years. All participants identified as Filipino or Filipino American and were either currently enrolled at a Texas college or university or had already graduated from college with a bachelor's degree. One participant identified as secondgeneration Filipino American, who was born in the United States. One participant was born in the Philippines and immigrated to the United States with her family when she was 6 years old. The remaining three participants were also first-generation Filipino Americans born in the Philippines, but immigrated to the United States when they were much older, between the ages of 12 and 16 years. Four participants identified as Catholic and one participant identified as Methodist.

\section{Procedures}

After obtaining approval from the Institutional Review Board, interviews were conducted. Interview questions asked participants to look retrospectively at their childhood experiences, which surrounded immigration from the Philippines and acculturation into mainstream American culture. Even participants who identified as second-generation Filipino Americans (born in the United States) expressed struggles with acculturation and strong ties to "Filipinized" Catholic and/or Methodist churches in their respective communities. Pseudonyms were chosen by each participant and interviews were recorded only if the participant gave permission. 
Faith and Filipino Immigration and Acculturation

Interviews focused primarily on participants' life experiences when they were children. Participants told stories about their childhood, growing up in the Philippines or the United States, and what they considered significant events in their lives. Follow-up questions were asked to clarify details of their histories. The latter part of the interviews transitioned into talking about the adverse experiences participants dealt with while in middle and high school and how those experiences influenced whether or how they sought help. Field notes and journaling were conducted extensively throughout the data collection, analysis, and writing processes. Also, given the personal experiences shared in the interviews, each participant was provided a location-specific resource list with contact information for spiritual, health, university (if applicable), and cultural services and organizations, should they feel the need to reach out.

To increase the trustworthiness of the qualitative study, member checks with each participant were conducted; engagement was further prolonged through catching up with each other via email or text after the conclusion of the interviews. Several study participants and the author are still in contact with each other ( $2 \frac{1}{2}$ years later at the time of this writing).

\section{Analysis}

To analyze the data, constant comparative method of qualitative data analysis was used to (a) prepare the data, (b) continue to familiarize the author with the data, (c) code data into categories, and (d) generate meaning (Glaser \& Strauss, 1967; Ruona, 2005).

\section{Data Preparation and Familiarization}

Data were prepared and organized collaboratively between the author and each participant. Audio recordings of interviews were transcribed and given to their respective study participants for review and clarification of information conveyed in each interview.

\section{Coding}

After participants reviewed them, the interview transcripts went through three levels of coding: open coding, axial coding, and selective coding (Strauss \& Corbin, 1990). The first round started with open coding each interview and used in vivo coding where necessary, for example, when one participant called her father "a ticking time bomb" to describe how she learned her coping mechanisms. In the second round of axial coding, these smaller codes were grouped into categories (Strauss \& Corbin, 1990). In the third round, interview data were taken through 
Faith and Filipino Immigration and Acculturation

selective coding to identify major themes. One theme that surfaced was faith with specific reliance on prayer as a source of comfort during the particularly difficult time of adjusting to mainstream American culture.

\section{Generating Meaning}

After identifying these major themes, the author reviewed the codes and themes with an expert in qualitative research and modified themes where necessary. The author also sent the study themes to participants to confirm the themes and messages in their stories.

\section{Results}

This study investigated the ways Christian faith influenced the immigration and acculturation experiences of Filipino American youth. All participants recalled different ways in which Christian faith at home helped them navigate their way through hardships and adapting to American norms. Consistent prayer and reliance on faith was the top answer for participants, when asked about how they dealt with the stresses of immigration and adjusting to Americanized ways of living. This section reports the major findings represented as the common themes of (a) using faith to establish community ties, (b) faith and dealing with major life transitions, (c) faith modeled by parents, and (d) faith as a coping mechanism.

\section{Using Faith to Establish Community Ties}

Christian faith was a powerful factor in the acculturation experiences of Filipino American youth. Especially during immigration when social and economic stability was non-existent or still growing, finding faith communities after immigrating to the United States helped participants and their families establish themselves. The faith communities allowed participants and their families to make connections with others who shared a similar faith identity, which is important in the acculturation process. Immigration is often an overwhelming experience that can leave immigrants feeling isolated and helpless. Where other ethnic groups may have small ethnic enclaves (e.g., Chinatown, Koreatown, etc.) to cushion their transitions to the United States, specifically in Texas, the Filipino immigrant community relies on faith-centered communities, which often revolve around church membership (Cherry, 2014). Like other ethnic groups, the Filipino faith community helped participants and their families acculturate to daily American norms and practices. In some cases, the Filipino faith community assisted participants' families in finding secure housing or jobs for participants' parents, as in the situation Jessica described: 
Faith and Filipino Immigration and Acculturation

We had to move because the apartment was increasing our rent. Good thing my parents [had friends] from church because they offered the house for like so much cheaper than we could afford, which helped us get by.

Jessica and her sister Nadine also expressed how their church community helped them when they were transitioning to the American school system. While education is functionally similar in the Philippines, socially there are very different norms and a greater use of English colloquialisms used in United States schools that are not as common in Philippine schools. One example can be seen in who and where Nadine asked for help with school work:

When it comes to like testing and whatever, our parents can't help with that because testing here [in the United States] is different from testing in the Philippines. So when it comes to like school stuff, project and stuff like that, I would ask ates and kuyas at church about school stuff. And there was this lab that I couldn't figure out. I just cried. I cried because I didn't know what to do. I didn't ask [for help] from my peers [at school]. I didn't ask my teacher. I didn't know why, but I could have, but I didn't. They might think that this lab is so easy, why aren't you getting it? Because [it] is the language barrier, because I didn't interpret it the same way that they did. Maybe it's me that's like wrong. And maybe they know how to do it. I feel like they know what the direction is telling them that I just didn't know because of that language barrier. So that's why I didn't reach out to them.

Nadine turned to ates (AH-tehs, Tagalog term meaning older sister or respected female friend) and kuyas (KOO-yahs, Tagalog term meaning older brother or respected male friend) for academic help. Her reluctance to ask her peers for help with school work exemplifies her fear and frustration with trying to perform well in school given the cultural and social differences between education in the Philippines and the United States. It was easier for Nadine to ask for help from someone she knew was of the same ethnic and faith community.

Participants' church communities were influential in helping them acculturate to the American school system and to also begin to establish roots at home. Their church community support structure lessened the economic burden for Nadine and Jessica's family to find suitable housing 
Faith and Filipino Immigration and Acculturation

when they were newly immigrated, and helped to mitigate the negative impacts of educational and language barriers that may be out of the school system's field of expertise.

\section{Faith and Dealing With Major Life Transitions}

Even participants who considered themselves second-generation Filipino Americans used their membership in their faith communities to help with major life transitions. One such transition was the transition from high school to college. Cookie came from a tight-knit Filipino American Methodist church community. Her experience with her church group played an influential role in her decision to choose the college she was currently attending. The faith community she was a part of provided her with the support structure to help her decide between two major universities in Texas. It was the college experience of Cookie's ate that influenced her college choice. Cookie reported that it was the sense of kinship and the sense of family that she most wanted to replicate in her college experience. Her church community group was a pivotal part of her middle school and high school years, and she wanted to attend a university that could most closely replicate that experience away from home.

Okay with church, it was definitely my life. Like church is definitely my life before college. My best friends were in the church and we all grew up together like a family. And we'd always go to this camp back at home and it'd be with other churches too, so we'd be really good friends with other churches too. They were all Filipino too, so I was avid church goer for sure. Overall [my university] is definitely oriented like my church group. Also the people here [in my university], like the Asian community is definitely really close-knit, you know? I definitely wanted that kind of feel, and so that's one of the reasons why I chose [my university] just culture and just family and stuff like that.

Kino expressed a similar impact of Christian faith. Experiencing natural disasters and watching his community go through hardships like the loss of homes, vehicles, or family members made his Catholic faith all the more important to Kino. His Catholic faith was critical in shaping the way he viewed disasters and adversity.

Yeah, especially growing up in the Philippines, you see a lot of suffering. I mean I was brought up in the Catholic faith, but there's a time when you start questioning the existence of God. $\mathrm{Hmm}$, why is there so much suffering? And I was like, well, 
Faith and Filipino Immigration and Acculturation

there's so much to guess. And that's when I relied on faith,

prayers; trying to key myself into listening to a being that is not

physically tangible. But relying on that faith, that's something-

there's a reason for a lot of these to happen. And the reasoning to

that is something good will come out of it. In all the dark places

you go it, there's always going to be that single light. And once

you get to the light, it's always good.

Major life changes, both positive and negative hold several different consequences for the people experiencing them. Relying on their Christian faith influenced all the subsequent decisions participants made. For Cookie, her church community influenced the college she chose to attend based on the close-knit family style relationship she had with her church group members. For Kino, his Catholic faith provided the grounding values that helped him persevere through natural disasters he experienced or saw his community experience. In both situations, their faith was a major motivator in the decisions they made.

\section{Faith Modeled by Parents}

While most participants identified as Catholic and had different experiences with how faith influenced their social and spiritual lives, all participants did report the modeling of faith in the home. All five participants recalled seeing faith, namely prayer and church attendance being modeled by their mothers. Mothers' Christian faith practices were the template from which participants drew their own faith practices. Angela recalled how her mother's faith helped her family stay oriented when dealing with new challenges in acculturating in the United States and dealing with the loss of Angela's grandmother.

Mom is a very spiritual person. So we were going through some tough times when we first in the early move of us in the States. And she gets really emotional talking about it. She always says that she had the church to go [to]. She always prayed that things would get better for us; financially it will get better for us. And she would always be like 'prayers help your lola' [LOH-lah, Tagalog term meaning grandmother]. It helped me. So I would never ever turn my back against it. 
Faith and Filipino Immigration and Acculturation

Notably, Kino's model for faith wasn't his parents. Instead it was his older siblings who looked after him and modeled Catholic faith practices for him. Shortly after he was born, both his parents left the Philippines and went ahead to the United States to establish a life for the family before bringing their children to the United States. Then shortly before Kino left the Philippines, he experienced the loss of his grandmother.

My grandma passed away-before my coming here in America she passed away. I was very sad. I didn't know what death was until then. I was probably nine or ten years old. And she was already suffering from Alzheimer's. She didn't even remember me. She doesn't even know me. But I knew about her. And it was sad to see somebody go. And to see somebody go so abruptly like that, that was my first experience of loss. I went to my siblings and talked to them about it. Faith definitely helps for me. I'm a very religious guy. I'm very spiritual. So praying to God about it and realizing that, it's okay. It's going to get better. It will get better.

Kino's experience of loss and then having to immigrate to start a new life in a different country presented a very unique social and emotional situation to deal with. Experiencing personal loss and then having to focus on acculturating to a new country and social norms can be quite difficult. But again, it was his faith and the modeling of faith by his older siblings that helped him through those difficult times. Later, when he came to live with his parents in the United States, his parents' Catholic faith practices served to reinforce what he learned as a younger boy in the Philippines.

\section{Faith as a Coping Mechanism}

Participants' faith was pivotal in helping them navigate through difficult childhood experiences and in some cases mental health problems. All participants reported experiencing varying levels of difficulties such as having trouble with school work, or problems with peers or boyfriends. On the more serious end, Angela suffered through serious suicide ideation and two unsuccessful attempts at taking her own life. In this case, she remembered the Catholic faith tenets her mother taught her. Angela would rely on prayer, more specifically and quite literally talking out loud to God to help her in her times of need. The importance of her mother's faith and in turn her own was so profound she reported experiencing her faith personified as a supernatural force. 
Faith and Filipino Immigration and Acculturation

But it's only when it really gets tough like finals and stuff or determining like I was going through a lot of stress with work and school. I was like, "Lord, please, just take the wheel. I don't know what to do anymore. "And even when I have those dark days with trying to attempt suicide and stuff like I have felt a physical hand. And I always think it's my grandparents like my lolo [LOH-loh, Tagalog term meaning grandfather] and lola. I felt them when I was trying to $O D$ on pills. I felt a hand like this. I was like, "Oh my god, what the heck is that?" And then I was just like I put them down.

Even at a subconscious level, Angela understood the seriousness and severity of her attempts to take her own life. According to Catholic doctrine the taking of your own life is considered a mortal and unforgivable sin. Angela's experience demonstrates the heavy reliance on her Catholic faith and what she perceived as a spiritual intercession.

\section{Discussion}

Based on the results of this study, Christian faith is an important coping factor for Filipino American youth. Christian faith allowed participants to feel a greater sense of connection to each other and to make connections with others in the United States. Christian faith also provided a conduit for participants to establish a sense of place and a shared identity with others. Their church communities eased the transition from the Philippines to the United States and provided socioemotional support for participants and their families. Unlike other ethnic groups that may have ethnic enclaves from which to draw support, no such place exists for Filipinos, particularly in Texas. The closest facsimile of such a community is the church, which has helped to unify Filipino American and Filipino immigrant communities in Texas under one common identity. This supports Cherry's (2014) findings concluding that the Filipino faith community goes hand-in-hand with Filipino community life. Thus, the need for participants like Cookie to find the same sense of community in college and Nadine's discomfort in asking for help from people outside her church community exemplify how influential faith is in Filipino life.

At the individual level, participants expressed how influential faith has been in shaping their worldview and in their day-to-day activities. Analysis revealed that commitment to their Christian faith, such as regular prayer, helped participants maintain a sense of self and gave them hope. For some participants who experienced intense adverse childhood experiences, their Christian faith was what got them through rough times. This was true even when 
situations were serious enough to seek professional medical care, as was Angela's case. All participants in this study relied primarily on their faith and the belief that God would see them through difficult times. Seeking help from God, or divine intercession-rather than seeking help from another person or a professional-was most often perceived by participants to be the way to find a solution to a serious problem. In many cases, participants admitted that asking for help from mental health professionals just wasn't an option for them. Instead they relied heavily on the modeling of faith in their families and their own personal practices. This is not surprising, and it supports additional research that reports Filipino Americans have the lowest rates of mental health care use, despite having one of the highest rates of insured households (McNamara \& Batalova, 2015; Nadal, 2011; Sanchez \& Gaw, 2007; Tompar-Tiu \& SustentoSeneriches, 1995).

\section{Limitations}

While the findings of this study are important, there are also several limitations to consider. First, participants of this study were all considered emerging adults (between 18 and 30 years old). They were asked to look retrospectively at experiences they had in childhood. In telling their stories, it was possible that participants misremembered or filled in details of their experiences that may not have happened. Additionally, participants were all college-educated individuals. There may have been a common theme surrounding immigration experiences, but the success of participants' families could also be a function of who was 'allowed' to immigrate and for what reasons. Historically, immigration laws such as the Tydings-McDuffie Act passed in 1934 placed restrictions on Philippine immigration to the United States, stating that only highly educated or highly specialized applicants were allowed to come to the United States to work or study. This type of historical policy set a precedent that could also have generational impacts for participants of this study.

\section{Implications for Future Practice}

Unlike other Asian and ethnic subgroups that may have large concentrations in cities, there is no center hub in Texas for Filipino American youth. Instead, there are smaller hubs comprised of churches with high Filipino American church membership and Filipino American youth who participate in church youth groups.

The results of this study and the nature of the Filipino church community hub have the potential to impact the youth development community in two distinct ways. First, based on the findings 
Faith and Filipino Immigration and Acculturation

in this study and the importance of faith, there is opportunity for youth development practitioners to begin to implement the core concept of belonging and the essential elements of (a) positive relationships with a caring adult, (b) an inclusive environment, and (c) a safe emotional and physical environment with Filipino youth who are often overlooked by the greater field of youth development (Martz, Mincemoyer, \& McNeely, 2016; Samuel \& Rose, 2011). Youth practitioners who take the time to understand the acculturation processes of Filipino American youth can be more effective in establishing and maintaining relationships with them. This can help youth feel like they are a part of a supportive community, especially if they are newly immigrated to the United States as were participants Nadine and Jessica.

Additionally, making such effort in developing relationships with Filipino American youth can also create an inclusive and safe environment within a mutually familiar setting (church). The experience of immigration has its own unique stressors that Filipino Americans as well as other immigrant children may not fully comprehend, but can feel acutely. Often the unfamiliarity to the United States and the loss of kinship networks and extended family exacerbate feelings of isolation and vulnerability for youth, especially when parents or guardians also feel overwhelmed and are unable to address the emotional and mental needs of their children (Pumariega, Rothe, \& Pumariega, 2005). If youth development practitioners understand how immigration and acculturation experiences are salient and influential, then Filipino American youth can feel comfortable sharing their experiences and expressing their feelings because practitioners will have created a safe space for them to do so.

Second, Christian faith is a crucial coping mechanism for youth going through difficult mental health experiences. Increasing faith-based, non-clinical alternatives for mental health issues within the Filipino American community could begin to dispel the stigma surrounding mental health issues and encourage family members, particularly parents, to be more open and supportive of their children's struggles. Further, faith-based mental health care has the opportunity to open the door for a more in-depth look at the state of Filipino American youth mental health in ways that might not be feasible in clinical situations. Cultural knowledge should also be blended into faith-based initiatives. There is a great opportunity for youth development and medical professionals to work with youth pastors and youth groups, especially those at churches with high attendance of Filipino American youth. In Angela's case, where clinical intervention may have been needed, stigma surrounding mental health care prevented her from seeking help. A faith-based approach that accommodated the nuances of Filipino American culture may have served her better, especially since she reported such a strong personification of her faith. Removing mental health care from a clinical setting and reframing it as spiritual 
care may make it easier for Filipino American youth to open up about personal difficulties. These insights can further remove stigma and begin to piece together a clearer picture of the state of Filipino American youth mental health.

This study revealed that Christian faith is an important aspect of Filipino American youths' lives. The participants in this study all demonstrated how they used their faith to cope with different situations surrounding their immigration and acculturation to the United States. This study also suggests that faith can possibly be the factor that helps remove the stigma from mental health issues. Collaborations among clinical and youth development practitioners and researchers to reframe mental health care into faith-based initiatives provides a great opportunity to help Filipino American youth address mental health issues more easily.

\section{References}

Baxter, P., \& Jack, S. (2008). Qualitative case study methodology: Study design and implementation for novice researchers. The Qualitative Report, 13(4), 544-559.

Cherry, S. M. (2014). Faith, family, and Filipino American community life. New Brunswick, NJ: Rutgers University Press.

Chou, R. S., \& Feagin, J. R. (2008). The myth of the model minority: Asian Americans facing racism. Boulder: Paradigm.

Creswell, J. W. (2013). Qualitative inquiry and research: Choosing among five approaches ( $3^{\text {rd }}$ ed.). Thousand Oaks, CA: Sage.

Espiritu, Y. L. 1995. Filipino American lives. Philadelphia, PA: Temple University Press.

Glaser, B. G., \& Strauss, A. L. (1967). The discovery of grounded theory: Strategies for qualitative research. New Brunswick, NJ: Aldine De Gruyter.

Gonzalez, J. J., III. (2009). Filipino American faith in action: Immigration, religion, and civic engagement. New York: New York University Press.

Lincoln, Y. S., \& Guba, E. G. (1985). Naturalistic inquiry. Thousand Oaks, CA: Sage.

Martz, J., Mincemoyer, C., \& McNeely, N. N. (2016). Essential elements of 4-H youth development programs: Curriculum and training guide. Chevy Chase, MD: National 4-H Council.

McNamara, K. \& Batalova, J. (2015). Filipino immigrants in the United States. Migration Information Source. Retrieved from http://www.migrationpolicy.org/article/filipino-immigrants-united-states-4

Merriam, S. B., \& Tisdell, E. J. (2015). Qualitative research: $A$ guide to design and implementation (4 ${ }^{\text {th }}$ ed.). Hoboken, NJ: John Wiley \& Sons.

Nadal, K. (2011). Filipino American psychology: A handbook of theory, research, and clinical practice. Hoboken, NJ: John Wiley \& Sons. 
Patton, M. (2015). Qualitative research \& evaluation methods: Integrating theory and practice ( $4^{\text {th }}$ ed.). Thousand Oaks, California: SAGE Publications.

Pumariega, A. J., Rothe, E., \& Pumariega, J. B. (2005). Mental health of immigrants and refugees. Community mental health journal, 41(5), 581-597. doi:10.1007/s10597-005-6363-1

Redfield, R., Linton, R., \& Herskovits, M. J. (1936). Memorandum for the study of acculturation. American anthropologist, 38(1), 149-152. doi:10.1525/aa.1936.38.1.02a00330

Ruona, W. E. (2005). Analyzing qualitative data. In R.A. Swanson \& E. F. Holton (Eds.), Research in organizations: Foundations and methods of inquiry (pp. 223-263). San Francisco, CA: BerrettKoehler.

Samuel, J. \& Rose, P. (2011). 4-H national Headquarters Fact Sheet: Essential Elements. Retrieved from : https://nifa.usda.gov/sites/default/files/resource/Essential_Elements.pdf

Sanchez, F., \& Gaw, A. (2007). Mental health care of Filipino Americans. Psychiatric Services, 58(6), 810815. doi:10.1176/ps.2007.58.6.810

Stake, R. E. (1995). The art of case study research. Thousand Oaks, CA: Sage.

Strauss, A. \& Corbin, J. (1990). Basics of qualitative research: Grounded theory procedures and techniques. Newbury Park, CA: Sage.

Tompar-Tiu, A., \& Sustento-Seneriches, J. (1995). Depression and other mental health issues: The Filipino American experience. San Francisco, CA: Jossey-Bass.

Yin, R. K. (2009). Case study research: Design and methods (4th ed.). Thousand Oaks, CA: Sage Publications, Inc. Retrieved from http://trove.nla.gov.au/version/18492216

Zong, J. \& Batalova, J. (2018). Filipino immigrants in the United States. Migration Information Source. Retrieved from http://www.migrationpolicy.org/article/filipino-immigrants-united-states 